Article

\title{
Antioxidant and Angiotensin-Converting Enzyme (ACE) Inhibitory Activities of Yogurt Supplemented with Lactiplantibacillus plantarum NK181 and Lactobacillus delbrueckii KU200171 and Sensory Evaluation
}

\author{
Eun-Deok Kim ${ }^{1}$, Hyun-Sook Lee ${ }^{2}$, Kee-Tae Kim ${ }^{1}$ and Hyun-Dong Paik ${ }^{1, *(D)}$ \\ 1 Department of Food Science and Biotechnology of Animal Resources, Konkuk University, Seoul 05029, Korea; \\ ked0823@konkuk.ac.kr (E.-D.K.); richard44@hanmail.net (K.-T.K.) \\ 2 Department of Foodservice Management and Nutrition, Sangmyung University, Seoul 51767, Korea; \\ leehs9292@smu.ac.kr \\ * Correspondence: hdpaik@konkuk.ac.kr; Tel.: +82-2-2049-6011
}

\section{check for} updates

Citation: Kim, E.-D.; Lee, H.-S.; Kim, K.-T.; Paik, H.-D. Antioxidant and Angiotensin-Converting Enzyme (ACE) Inhibitory Activities of Yogurt Supplemented with Lactiplantibacillus plantarum NK181 and Lactobacillus delbrueckii KU200171 and Sensory Evaluation. Foods 2021, 10, 2324. https://doi.org/10.3390/ foods10102324

Academic Editor: Maria Aponte

Received: 1 September 2021

Accepted: 28 September 2021

Published: 30 September 2021

Publisher's Note: MDPI stays neutral with regard to jurisdictional claims in published maps and institutional affiliations.

Copyright: (c) 2021 by the authors. Licensee MDPI, Basel, Switzerland. This article is an open access article distributed under the terms and conditions of the Creative Commons Attribution (CC BY) license (https:// creativecommons.org/licenses/by/ $4.0 /)$.

\begin{abstract}
This study was carried out to develop a functional yogurt with inhibitory effects on angiotensin-converting enzyme (ACE) and antioxidant activity using various probiotic strains. Yogurts were prepared using a commercial LAB freeze-dried product and probiotics. Yogurt with only commercial LAB product as control group (C) and probiotics supplemented with Lacticaseibacillus rhamnosus GG KCTC 12202 BP, as a reference group (T1), Lactiplantibacillus plantarum KU15003 (T2), Lactiplantibacillus plantarum KU15031 (T3), Lactiplantibacillus plantarum NK181 (T4), and Lactobacillus delbrueckii KU200171 (T5). The T5 sample showed high antioxidant activities $(86.5 \pm 0.3 \%$ and $39.3 \pm 1.0 \%$ in DPPH and ABTS assays, respectively). The T4 sample had the highest ACE inhibitory activity $(51.3 \pm 10.3 \%)$. In the case of sensory evaluation, the T4 and T5 samples did not show a significant difference $(p>0.05)$ compared to the reference group. These results suggest that $L$. plantarum NK181 and L. delbrueckii KU200171 can be used in the food industry especially dairy to improve health benefits for hypertensive patients.
\end{abstract}

Keywords: probiotics; yogurt; antioxidant; ACE inhibition; sensory evaluation

\section{Introduction}

The etymology of probiotics is derived from the Greek word meaning "pro-life" [1]. The definition of probiotics is "a preparation of or a product containing viable, defined microorganisms in sufficient numbers, which alter the microflora in a compartment of the host and by that exert beneficial health effects in this host." [2].

The functional effects of probiotics have been extensively studied. Oelschlaeger [3] reported that the effects of probiotics might be classified into three modes of action. First, probiotic effects can be based on actions that affect microbial products such as toxins and host products such as bile salts and food ingredients. Second, probiotics can also directly affect other microbes, symbiotic and/or pathogenic microbes. Finally, Probiotics can modulate the host's defenses, including the immune system. This mode of action is of paramount importance not only for the prevention and treatment of infectious diseases but also for the treatment of chronic inflammation of the digestive tract or parts thereof. In addition, probiotics have anticancer properties [4]. According to Lee et al. [5], Lactobacillus plantarum KU 200656 isolated from kimchi showed anti-pathogenic effects. In addition, L. fermentum strains may have potential cholesterol-lowering effects [6], and Liu et al. [7] reported that probiotics have a role in reducing risks associated with cardiovascular disease.

Yogurt is one of the most general fermented foods worldwide [8]. It is a coagulated milk product from lactic acid bacteria (LAB) fermentation and contains proteins, such as casein [9]. Additionally, yogurt has good health benefits because of its bioactive protein 
hydolysates produced during fermentation [10,11]. In particular, yogurt has been shown to have an effect on diseases such as chronic illness, heart diseases, cancer, and diabetes [12,13]. However, these functional effects differ according to the variety of probiotic strains used.

Cardiovascular diseases, such as hypertension, often occur due to oxidative stress caused by various free radicals [14]. In particular, lung angiotensin-converting enzyme (ACE) plays an important role in blood pressure regulation, and inhibition of this enzyme promotes vasodilator production and sympathetic nervous system regulation. [15]. Recently, many pharmaceutical treatments have been developed to treat these chronic diseases. However, these methods often lead to treatment resistance. Therefore, there is a trend toward finding natural substances with relatively few side effects [16]. Fermented milk is considered a food that can have a positive effect on chronic diseases such as high blood pressure. In fact, many studies have shown that probiotics in fermented foods have an ACE inhibitory effect as well as antioxidant effects [10,17-19].

Thus, the purposes of this study were (1) to evaluate functional yogurt with ACE inhibition and antioxidant effects, and (2) to perform sensory evaluation of the products. In this study, we used the probiotic Lacticaseibacillus rhamnosus GG KCTC 12202BP, Lactiplantibacillus plantarum KU15003, Lactiplantibacillus plantarum KU15031, Lactiplantibacillus plantarum NK181, and Lactobacillus delbrueckii KU200171.

\section{Materials and Methods}

\subsection{Microorganisms and Culture Conditions}

The strains used in this study were Lacticaseibacillus rhamnosus GG KCTC 12202BP as a commercial reference strain, Lactiplantibacillus plantarum KU15003 and Lactiplantibacillus plantarum KU15031 (both isolated from kimchi), Lactiplantibacillus plantarum NK181 isolated from jeotgal (traditional Korean fermented food), and Lactobacillus delbreuckii KU200171 isolated from kimchi. These probiotics were isolated as described by Lee et al. [20]. All strains were cultured and maintained in de Man, Rogosa, and Sharpe (MRS) broth (BD BBL, Franklin Lakes, NJ, USA) at $37^{\circ} \mathrm{C}$.

\subsection{Yogurt Sample Preparation}

The yogurt was made with the method of Sah et al. [16] with few modifications. Briefly, six batches of milk bases were prepared by reconstitution with skim milk powder $\left(12 \% w / w\right.$, Seoul Milk, Seoul, Korea), $2 \%(w / w)$ FOS $\left(\mathrm{C}_{6} \mathrm{H}_{10} \mathrm{O}_{5}\right)_{\mathrm{n}}(n>10)$ (Cheil Jedang, Seoul, Korea) and water. The samples were pasteurized at $90{ }^{\circ} \mathrm{C}$ for $10 \mathrm{~min}$. After cooling to $40{ }^{\circ} \mathrm{C}$, all the mixtures were inoculated with a commercial $\mathrm{LAB}$ mixture $(0.01 \% w / w$, ABT-B; Culture Systems, Inc., Mishawaka, IN, USA). Except for the control (C), probiotics (colony count of the inoculum, $10^{7} \mathrm{CFU} / \mathrm{mL}$ ) were inoculated to mixtures, respectively. Fermentation was terminated when the $\mathrm{pH}$ reached $4.4 \pm 0.1$. The yogurts were gently cooled and stored at $4{ }^{\circ} \mathrm{C}$ for a day. After the samples were ripened, all experiments were performed. The samples were named as: $\mathrm{C}$, control with only commercial starter culture; T1, L. rhamnosus GG KCTC 12202BP; T2, L. plantarum KU15003; T3, L. plantarum KU15031; T4, L. plantarum NK181; and T5, L. delbrueckii KU200171.

\section{3. $\mathrm{pH}$ and LAB Viability of Yogurt}

The $\mathrm{pH}$ values of the samples were measured using a $\mathrm{pH}$ meter (InoLab $\mathrm{pH}$ 7110; Xylem Analytics Germany Sales. GmbH \& Co. KG, Weilheim, Germany). Cell counts of all yogurt samples were determined during the fermentation period using the method described by Habibi et al. [15]. Each fermented milk was diluted with $0.1 \%$ peptone water every $3 \mathrm{~h}$ during fermentation. The diluted samples were inoculated at MRS agar at $37^{\circ} \mathrm{C}$. The MRS agar plates were cultivated for $48 \mathrm{~h}$.

\subsection{Preparation of Water-Soluble Extracts}

Water-soluble extracts (WSEs) were prepared using the method described by Sah et al. and Kariyawasam and Lee $[11,16]$ with a few modifications. The $30 \mathrm{~g}$ of yogurt 
was centrifuged at $14,000 \times g$ at $4{ }^{\circ} \mathrm{C}$ for $30 \mathrm{~min}$ to get supernatant. The supernatant filtered through a $0.45 \mu \mathrm{m}$ membrane filter was freeze-dried and stored at less than $-80^{\circ} \mathrm{C}$. In addition, the lyophilisates were dissolved with distilled water to analyze biological activity [11]. Through the Bradford assay using bovine serum albumin (0.1-1.2 mg/mL), the protein contents of dissolved WSE lyophilisates were fixed $(0.5 \mathrm{mg}$ of protein $/ \mathrm{mL})$.

\subsection{Antioxidant Activity}

The antioxidant activity of WSEs was confirmed using both 2,2-diphenyl-2-picrylhydrazyl (DPPH; Sigma-Aldrich Co., Steinheim, Germany) and 2,2-azinobis (3-ethylbenzothiazoline6-sulfonic acid) di-ammonium salt (ABTS; Sigma-Aldrich Co., Steinheim, Germany) radical scavenging assays.

\subsubsection{DPPH Assay}

The DPPH assay was performed as previously described [21] with slight modifications. WSE was mixed with $750 \mu \mathrm{L}$ of $100 \mu \mathrm{M}$ DPPH. The reaction was played in the dark at $25^{\circ} \mathrm{C}$ for $20 \mathrm{~min}$. The absorbance was measured at $517 \mathrm{~nm}$ using a spectrophotometer (Optizen 2120 UV; Mecasys Co., Ltd., Daejeon, Korea). Each sample was tested in triplicate. The DPPH radical scavenging activity was computed using the following formula:

$$
\text { DPPH radical scavenging activity }(\%)=\left(1-\mathrm{A}_{\text {sample }} / \mathrm{A}_{\text {control }}\right) \times 100
$$

$\mathrm{A}_{\text {control }}$ and $\mathrm{A}_{\text {sample }}$ are the absorbances of the control (distilled water) and WSE, respectively.

\subsubsection{ABTS Assay}

The ABTS assay was performed by the modified method of Yang et al. [22]. The solution was prepared with $14 \mathrm{mM}$ ABTS and $5 \mathrm{mM} \mathrm{K}_{2} \mathrm{~S}_{2} \mathrm{O}_{8}$; the solution was stored at $25{ }^{\circ} \mathrm{C}$ for $18 \mathrm{~h}$ with light blocked.

The prepared solution was diluted with $0.1 \mathrm{M}$ sodium phosphate buffer ( $\mathrm{pH}$ 7.4) until its absorbance approached $0.7 \pm 0.05$ at $734 \mathrm{~nm}$. The $20 \mu \mathrm{L}$ of WSE was added to $980 \mu \mathrm{L}$ of ABTS solution. Then, the mixture was incubated in the dark at $25^{\circ} \mathrm{C}$ for $20 \mathrm{~min}$. Absorbances of all samples were measured in triplicate at $734 \mathrm{~nm}$. The radical scavenge activity in ABTS assay was determined using the following formula:

$$
\text { ABTS radical scavenging activity }(\%)=\left(1-\mathrm{A}_{\text {sample }} / \mathrm{A}_{\text {control }}\right) \times 100
$$

$\mathrm{A}_{\text {control }}$ and $\mathrm{A}_{\text {sample }}$ are the absorbances of the distilled water and WSE as samples, respectively.

\subsection{Determination of ACE Inhibitory Activity}

The ACE inhibitory activity of WSEs was confirmed by the methods of Cushman et al. and Kariyawasam and Lee [11,23] with slight modifications. Each $50 \mu \mathrm{L}$ of WSE was added to $150 \mu \mathrm{L}$ of $0.1 \mathrm{U} / \mathrm{mL}$ ACE solution and $100 \mu \mathrm{L}$ of $0.1 \mathrm{M}$ sodium borate buffer containing $0.3 \mathrm{M} \mathrm{NaCl}$ at $\mathrm{pH} 8.3$. The mixture was kept at $37^{\circ} \mathrm{C}$ for $10 \mathrm{~min}$. ACE enzyme reagent used in this study was produced from rabbit lung and purchased from Sigma-Aldrich. A $50 \mu \mathrm{L}$ of $5 \mathrm{mM}$ hippuryl-L-histidyl-L-leucine (HHL; Sigma-Aldrich, St. Louis, MO, USA) in $0.1 \mathrm{M}$ sodium borate buffer containing $0.3 \mathrm{M} \mathrm{NaCl}(\mathrm{pH}$ 8.3) was added to the reaction mixture and stood at $37^{\circ} \mathrm{C}$ for $30 \mathrm{~min}$. The reaction was stopped by adding $250 \mu \mathrm{L}$ of $1 \mathrm{~N}$ $\mathrm{HCl}$. In addition, $200 \mu \mathrm{L}$ of ethyl acetate was added to extract the liberated hippuric acid during the reaction. After mixing with a vortex mixer, the samples were centrifuged at $3000 \times g$ at $4{ }^{\circ} \mathrm{C}$ for $30 \mathrm{~min}$. After the supernatants (ethyl acetate layer) were taken, ethyl acetate was completely evaporated using a water bath at $90^{\circ} \mathrm{C}$. The residue was dissolved in $1.0 \mathrm{~mL}$ of sodium borate buffer and refrigerated to $25^{\circ} \mathrm{C}$. All samples' absorbances were 
measured in triplicate at $228 \mathrm{~nm}$. The results were determined as inhibitory activity on ACE (\%) using the following formula:

$$
\text { Inhibitory activity on } \mathrm{ACE}(\%)=\left(1-\mathrm{A}_{\text {sample }} / \mathrm{A}_{\text {control }}\right) \times 100
$$

$\mathrm{A}_{\text {control }}$ and $\mathrm{A}_{\text {sample }}$ are the absorbances of the control (buffer solution) and WSE, respectively.

\subsection{Sensory Analysis}

Following the results of antioxidant and ACE inhibitory activities (discussed in Section 3) only C, T1, T4, and T5 were used for sensory evaluation. Each yogurt was chilled at $4{ }^{\circ} \mathrm{C}$ for at least $24 \mathrm{~h}$ for ripening. Sensory analysis was performed by 31 trained panelists. Panels were trained with Sensory analysis-Methodology-Initiation and training of assessors in the detection and recognition of odors (ISO 5496:2006) [24]. The method was approved by the Institutional Review Board (approval number: IRB-SMU-C-2020-4004, Korea). Quantitative descriptive analysis was performed to evaluate the differences in the sensory characteristics of the yogurt samples with probiotics. The color, taste, texture, flavor, and overall preference of each yogurt were measured. Water and plain bread were provided between the samples as a palette cleanser.

\subsection{Statistical Analysis}

Using IBM SPSS statistics 18 software, all data were explained with statistical analyses. Data were assessed using a one-way analysis of variance (ANOVA). Significant differences between the means were indicated by Duncan's multiple range test at the $p<0.05$ level.

\section{Results and Discussion}

\section{1. $p H$ and Viability of LAB of Yogurt Samples}

The $\mathrm{pH}$ values are shown in Figure 1. All the samples showed a decrease in $\mathrm{pH}$ during fermentation; the $\mathrm{pH}$ was reduced to $4.4 \pm 0.1 \mathrm{in} 9 \mathrm{~h}$. Despite the difference in $\mathrm{LAB}$ composition, the $\mathrm{pH}$ values of yogurts with probiotics did not differ significantly $(p>0.05)$ compared to that of the yogurt with only the commercial starter culture. The viable cell counts in yogurt during fermentation are shown in Figure 2; they ranged from 6.3 to $9.1 \log \mathrm{CFU} / \mathrm{mL}$. In the viability of $\mathrm{LAB}$, none of the data showed significant values $(p>0.05)$. The probiotics have to remain viable in food products above a threshold level to confirm probiotic health benefits. The minimum level of viable LAB should be at least $10^{6} \mathrm{CFU} / \mathrm{g}$ [25]. All the results showed reasonable values at the end of fermentation. Therefore, these probiotics were determined to be suitable as fermented strains of yogurt and to have potential functional effects.

\subsection{Antioxidant Activities of Yogurts}

The results of antioxidant activities are shown in Figure 3.

The DPPH assay is a simple and accurate method for confirming antioxidant effects [26]. The antioxidant activities recorded via DPPH assay for C and T1-T5 were $62.84 \pm 5.17 \%$, $71.33 \pm 6.81 \%, 72.72 \pm 5.82 \%, 75.00 \pm 3.38 \%, 80.77 \pm 1.30 \%$, and $86.49 \pm 0.28 \%$, respectively. The $\mathrm{IC}_{50}$ values of $\mathrm{C}$ and T1-T5 were $0.38 \mathrm{mg} / \mathrm{mL}, 0.32 \mathrm{mg} / \mathrm{mL}, 0.32 \mathrm{mg} / \mathrm{mL}, 0.30 \mathrm{mg} / \mathrm{mL}$, $0.29 \mathrm{mg} / \mathrm{mL}$ and $0.28 \mathrm{mg} / \mathrm{mL}$, respectively. 


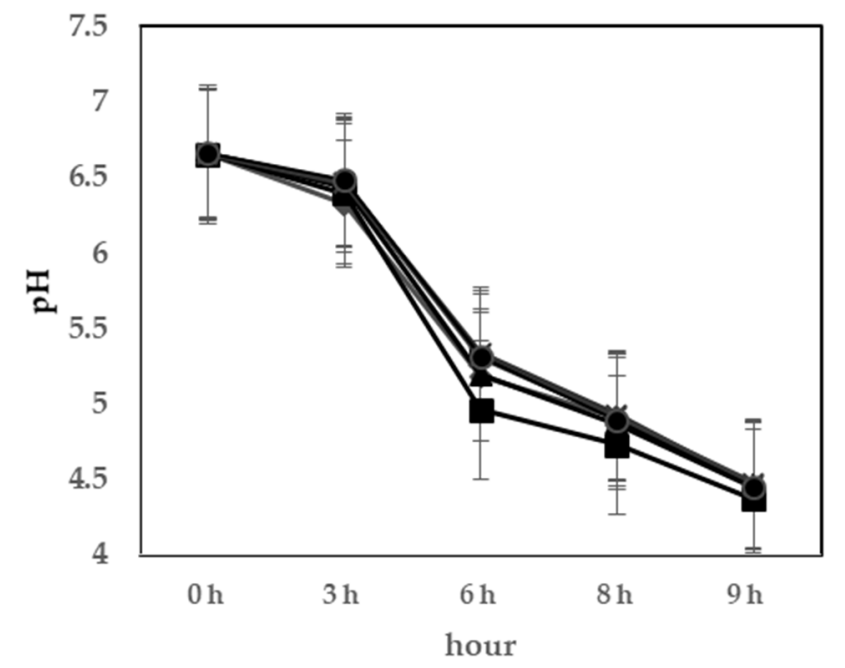

Figure 1. Changes in $\mathrm{pH}$ during fermentation at $40{ }^{\circ} \mathrm{C}$. $\diamond$, control yoghurt without probiotics $(\mathrm{C})$; 口, L. rhamnosus GG KCTC 12202BP(T1); $\mathbf{\Delta}$, L. plantarum KU15003 (T2); × , L. plantarum KU15031(T3); *, L. plantarum NK181(T4); •, L. delbrueckii KU200171(T5).

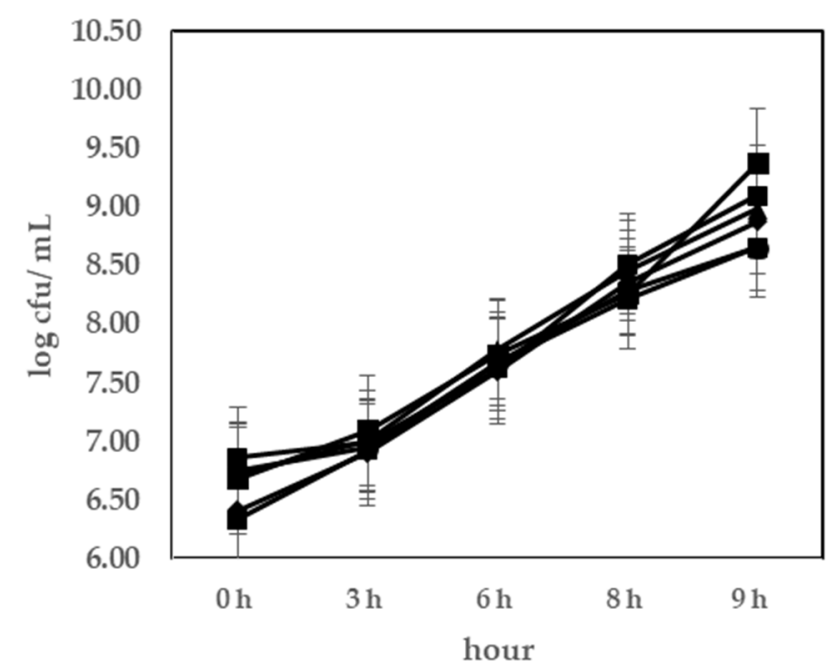

Figure 2. $\mathrm{LAB}$ bacterial cell numbers during fermentation at $40{ }^{\circ} \mathrm{C}$. $\bullet$, control yoghurt without probiotics (C); $\mathbf{\square}$, L. rhamnosus GG KCTC 12202BP(T1); ム, L. plantarum KU15003 (T2); ×, L. plantarum KU15031(T3); *, L. plantarum NK181(T4); •, L. delbrueckii KU200171(T5).

The ABTS assay was also used to measure antioxidant activity. It measures the degree of inhibition of ABTS cations through the color change of a solution in the presence of antioxidants [27]. The antioxidant activities using the ABTS assay for C and T1-T5 were $37.65 \pm 0.67 \%, 38.80 \pm 0.62 \%, 38.00 \pm 0.43,38.25 \pm 0.34 \%, 38.50 \pm 0.41 \%$, and $39.31 \pm 0.99 \%$, respectively. The $\mathrm{IC}_{50}$ values of $\mathrm{C}$ and $\mathrm{T} 1-\mathrm{T} 5$ were $0.66 \mathrm{mg} / \mathrm{mL}$, $0.65 \mathrm{mg} / \mathrm{mL}, 0.65 \mathrm{mg} / \mathrm{mL}, 0.64 \mathrm{mg} / \mathrm{mL}, 0.65 \mathrm{mg} / \mathrm{mL}$, and $0.64 \mathrm{mg} / \mathrm{mL}$, respectively. The yogurt with L. delbrueckii KU200171 exhibited higher radical scavenging potency in all experiments than the yogurt with other probiotic strains. In this study, two methods, DPPH and ABTS, were used to evaluate antioxidant activity. The radical scavenging ability of antioxidants for DPPH and ABTS radicals may differ due to differences in solubility and diffusivity in the reaction medium. In addition, DPPH acts as an oxidative substrate and a reaction indicator. Spectral interference problems can easily arise. On the other side, ABTS is soluble in both aqueous and organic media. The radical scavenging activity of hydrophilic and lipophilic antioxidants can be evaluated using this method [28]. For this reason, it is considered that there is a difference between the results of DPPH and those 
of ABTS; in DPPH, T5 had a value about $10 \%$ higher than that of the $\mathrm{C}$, and there was a significant difference in ABTS, but it had a similar value.

Milk proteins have been known as potential materials of biologically active peptides [29]. Donkor et al. [19] showed differences in bioactive peptides between yogurt starter cultures and probiotics.

Because of bioactive peptides released during fermentation, the antioxidant activities of WSEs were shown. Furthermore, the diverse antioxidant activity of yogurt WSE suggests that its radical scavenging activity depends on the difference of LAB strains and their individual enzyme patterns [11]. Thus, the antioxidant capacity of hydrolysates for the same substrate depends on the type of enzyme from the LAB, as specific proteases are complex in the hydrolysis of specific peptide bonds [16]. Specifically, Kudoh et al. [30] found the amino acid sequence of milk protein in fermented milk with L. delbrueckii ssp. bulgaricus. These amino acid sequences affect radical scavenging activity. Therefore, the results of this study conform to those reported in previous studies.
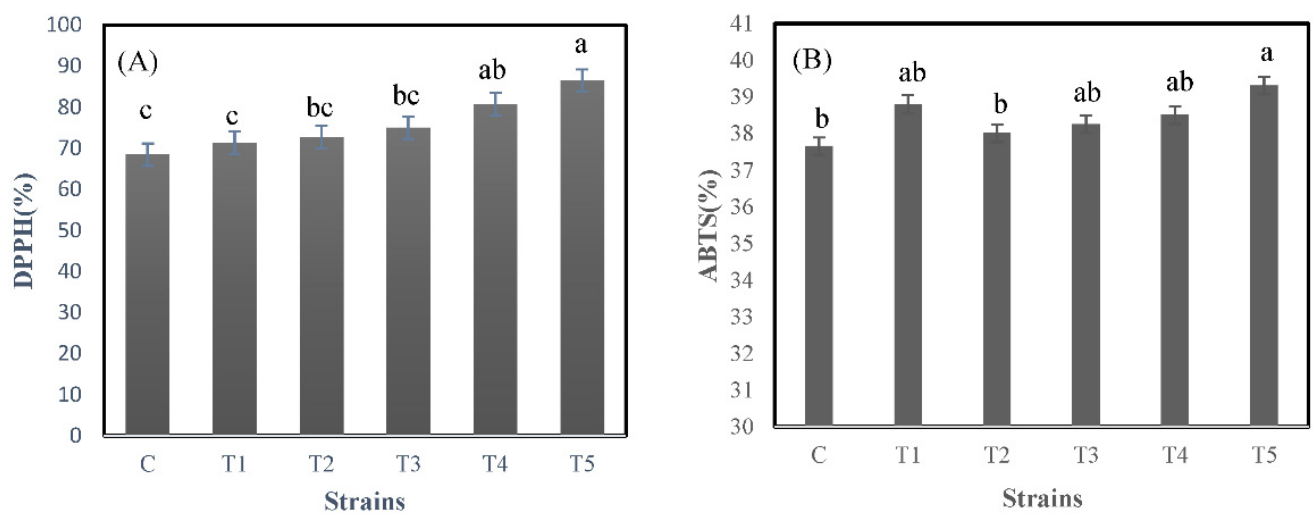

Figure 3. (A) DPPH and (B) ABTS radical scavenging assays of the water-soluble extracts (WSEs) from yogurt. C, control yogurt without probiotics; T1, L. rhamnosus GG KCTC 12202BP; T2, L. plantarum KU15003; T3, L. plantarum KU15031; T4, L. plantarum NK181; T5, L. delbrueckii KU200171. Means from different yogurt expressed by lowercase letters $(a-c)$ are significantly different $(p<0.05)$.

\subsection{ACE Inhibition Activities of Yogurt}

The ACE inhibition activity of the WSEs is shown in Figure 4. The activities of C and T1-T5 were $26.06 \pm 8.61 \%, 35.60 \pm 3.78 \%, 41.36 \pm 4.30 \%, 37.95 \pm 4.21 \%, 51.32 \pm 10.30 \%$, and $45.09 \pm 4.58 \%$, respectively. The $\mathrm{IC}_{50}$ values of $\mathrm{C}$ and $\mathrm{T} 1-\mathrm{T} 5$ were $2.28 \mathrm{mg} / \mathrm{mL}$, $0.89 \mathrm{mg} / \mathrm{mL}, 0.68 \mathrm{mg} / \mathrm{mL}, 0.79 \mathrm{mg} / \mathrm{mL}, 0.48 \mathrm{mg} / \mathrm{mL}$, and $0.64 \mathrm{mg} / \mathrm{mL}$, respectively. The $\mathrm{IC}_{50}$ values were lower in the group to which probiotics were added compared to $\mathrm{C}$. This suggests that yogurt with probiotics has an ACE inhibitory effect. Donkor et al. [19] reported that yogurts with probiotics had higher values than the control group. In this study, T4 and T5 showed significantly higher ACE inhibitory activities than C ( $p<0.05$; Figure 4$)$. ACE converts angiotensin I to angiotensin II, which is involved in maintaining high blood pressure [31]. The bioactive peptides were known to have ACE inhibitory activities [18]. Cavalheiro et al. [32] reported that the higher the protein content in fermented milk, the higher the ACE inhibitory effect. Yogurt or cheese fermented with various LAB-released ACE inhibitory peptides with specific amino acid sequences [33]. Moreover, Vasiljevic and Snah [34] reported that $\beta$-casein hydrolysates by L. delbrueckii spp. bulgaricus had ACE inhibitory effects. As such, it can be seen that the hydrolyzed proteins made through probiotics exhibit an ACE inhibitory effect. Kariyawasam et al. [11] synbiotic yogurt had a higher ACE inhibitory activity than non-synbiotic yogurt. In this study, all samples were made with skim milk powder and fructooligosaccharide. Habibi et al. [15] suggested that the ACE inhibitory activities are influenced by fat content; that is, non-fat yogurt had higher ACE inhibitory activity than that containing fat. Habibi et al. [35] suggested that ACE inhibition effects depend on the presence of prebiotics. When yogurt contained prebiotics, the ACE inhibitory activities were higher than those of other samples [35]. 
Erkaya-Kotan [36] concluded that the degree of enzyme activity inhibition was correlated with the phenol content as well as the prebiotic content using orange fiber. Furthermore, soy yogurt with probiotics was shown to have a substantial increase in ACE inhibitory activity compared with the control samples produced by commercial yogurt culture [37]. As such, it can be seen that ACE inhibition is affected not only by probiotics but also by several other factors. Based on these previous studies, we attempted to obtain a high ACE inhibitory effect through the addition of prebiotics and fermentation using only skim milk powder. In this study, T4 with L. plantarum NK181 and T5 with L. delbrueckii KU200171 had a significantly higher $(p<0.05)$ ACE inhibitory activity compared to the $C$. These results are considered to be dependent on previous studies. Based on these results, L. plantarum NK181 and L. delbrueckii KU200171 were considered good probiotics for dairy products with ACE inhibitory activities.

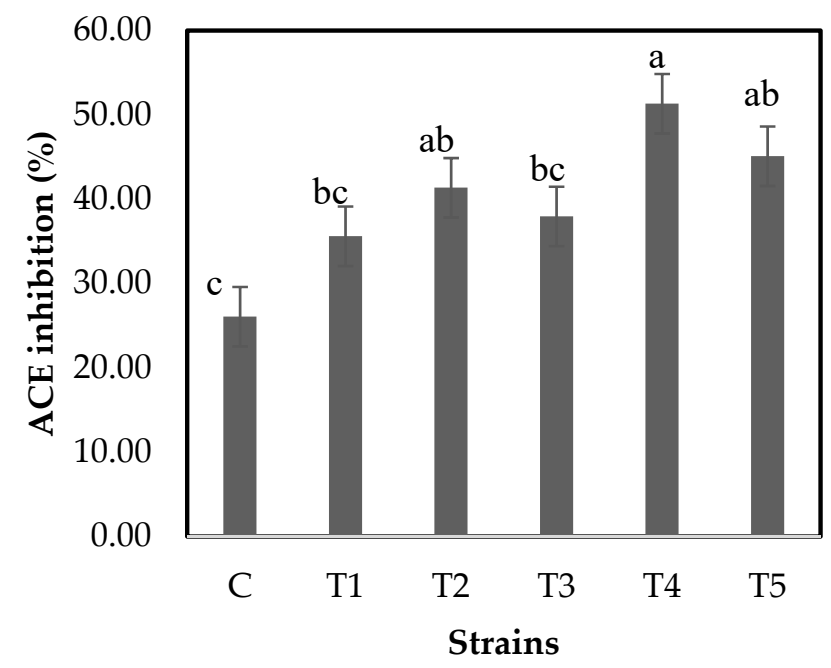

Figure 4. ACE inhibitory activity of the water-soluble extracts (WSEs) from yogurt. ABT-B, control yogurt without probiotics; T1, L. rhamnosus GG KCTC 12202BP; T2, L. plantarum KU15003; T3, L. plantarum KU15031; T4, L. plantarum NK181; T5, L. delbrueckii KU200171. Means from different yogurt expressed by lowercase letters $(\mathrm{a}-\mathrm{c})$ are significantly different $(p<0.05)$.

\subsection{Sensory Evaluation}

Based on the higher antioxidant and ACE inhibitory activities of T4 and T5 compared to those of the other samples, they were selected as test samples. Because the $C$ was prepared only with a starter and T1 was treated with L. rhamnosus GG, which is a commercial probiotic strain, these two groups were considered as reference groups. All samples were subjected to sensory evaluation for color, taste, texture, flavor, and overall acceptability. The results are presented in Table 1. For all sensory evaluations, except for color, T4 and T5 were given higher values than $C$. However, there were no significant differences between all samples $(p>0.05)$. Karimi et al. [25] reported the expression of various flavors and tastes in fermented foods according to various probiotics. For example, L. rhamnosus SP3 expressed a fruity flavor in cheese. Although there is a slight difference, compared to C, the reason that the yogurt with probiotics showed good results in sensory evaluation is thought to be due to the influence of the strains. It is considered that this functional yogurt is suitable for sensory evaluation. In addition, the stability of L. plantarum NK181 and L. delbrueckii KU200171, such as bile resistance, acid resistance, and intestinal adhesion ability, has been confirmed in previous studies [20,38]. Therefore, these probiotics are considered useful LAB in the dairy industry. 
Table 1. Consumer panelist ratings for the yogurt samples on a 7-point scale.

\begin{tabular}{ccccc}
\hline \multirow{2}{*}{$\begin{array}{c}\text { Sensory } \\
\text { Evaluation }\end{array}$} & \multicolumn{4}{c}{ Samples } \\
\cline { 2 - 5 } & C & T1 & T4 & T5 \\
\hline Color & $5.71 \pm 1.35$ & $5.61 \pm 1.33$ & $5.39 \pm 1.31$ & $5.48 \pm 1.23$ \\
Taste & $4.10 \pm 1.33$ & $4.19 \pm 1.35$ & $4.58 \pm 1.31$ & $4.55 \pm 1.39$ \\
Texture & $4.80 \pm 1.40$ & $5.19 \pm 1.11$ & $5.29 \pm 1.30$ & $5.06 \pm 1.50$ \\
Flavor & $4.90 \pm 1.04$ & $5.39 \pm 0.99$ & $5.42 \pm 0.99$ & $5.39 \pm 0.88$ \\
Overall & $4.16 \pm 1.37$ & $4.58 \pm 1.20$ & $4.61 \pm 1.36$ & $4.74 \pm 1.29$ \\
\hline
\end{tabular}

Values are means \pm standard deviation $(n=31)$; Means are not significantly different $(p>0.05)$. $C$, control yogurt without probiotics; T1, L. rhamnosus GG KCTC 12202BP; T4, L. plantarum NK181; T5, L. delbrueckii KU200171.

\section{Conclusions}

This study confirmed the functionality of yogurt fermented using various probiotics. Compared with C, all probiotic yogurts showed antioxidant activities, and ACE inhibitory effects, especially T4 treated with L. plantarum NK181 and T5 treated with L. delbrueckii KU200171 showed significantly higher activities $(p<0.05)$ than any other groups tested in this study. Sensory evaluation of those two samples showed no significant difference when compared with the commercial group. Recently, with increasing interest in promoting health through food, probiotics with inhibitory effects on angiotensin-converting enzymes are becoming attractive to the functional food industry for preventing adult chronic diseases, especially for hypertension patients. Furthermore, it is expected that this study will be useful in the application of functional fermented dairy materials in the pharmaceutical industry.

Author Contributions: Conceptualization, E.-D.K. and H.-D.P.; methodology, E.-D.K. and H.-S.L.; validation, E.-D.K.; formal analysis, E.-D.K.; investigation, E.-D.K.; resources, K.-T.K.; data curation, E.-D.K.; writing—original draft preparation, E.-D.K.; writing—review and editing, K.-T.K.; visualization, K.-T.K.; supervision, H.-D.P.; project administration, H.-D.P. All authors have read and agreed to the published version of the manuscript.

Funding: This research received no external funding.

Institutional Review Board Statement: The study was conducted according to the guidelines of the Declaration of Helsinki and approved by the Institutional Review Board (approval number: IRB-SMU-C-2020-4-004) of Sangmyung University, Korea.

Informed Consent Statement: Not applicable.

Data Availability Statement: Data sharing is not applicable.

Conflicts of Interest: The authors declare no conflict of interest.

\section{References}

1. Sarkar, S. Effect of probiotics on biotechnological characteristics of yoghurt. Br. Food J. 2008, 110, 717-740. [CrossRef]

2. Schrezenmeir, J.; de Vrese, M. Probiotics, prebiotics, and synbiotics-approaching a definition. Am. J. Clin. Nutr. 2001, 73, 361-364. [CrossRef]

3. Oelschlaeger, T.A. Mechanisms of probiotic actions-A review. Int. J. Med. Microbiol. 2010, 300, 57-62. [CrossRef]

4. Soccol, C.R.; de Souza Vandenberghe, L.P.; Spier, M.R.; Medeiros, A.B.; Yamaguishi, C.T.; Lindner, J.D.D. The potential of probiotics: A review. Food Technol. Biotechnol. 2010, 48, 413-434.

5. Lee, J.E.; Lee, N.K.; Paik, H.D. Antimicrobial and anti-biofilm effects of probiotic Lactobacillus plantarum KU200656 isolated from kimchi. Food Sci. Biotechnol. 2021, 30, 97-106. [CrossRef]

6. Meltem, A.O.; Ayse, G. Lactobacillus fermentum strains from human breast milk with probiotic properties and cholesterol-lowering effects. Food Sci. Biotechnol. 2019, 28, 501-509.

7. Liu, D.M.; Guo, J.; Zeng, X.A.; Sun, D.W.; Brennan, C.S.; Zhou, Q.X.; Zhou, J.S. The probiotic role of Lactobacillus plantarum in reducing risks associated with cardiovascular disease. Int. J. Food Sci. Technol. 2017, 52, 127-136. [CrossRef]

8. Jeong, C.H.; Ryu, H.; Zhang, T.; Lee, C.H.; Seo, H.G.; Han, S.G. Green tea powder supplementation enhances fermentation and antioxidant activity of set-type yogurt. Food Sci. Biotechnol. 2018, 27, 1419-1427. [CrossRef] [PubMed] 
9. Batista, A.L.; Silva, R.; Cappato, L.P.; Almada, C.N.; Garcia, R.K.; Silva, M.C. Quality parameters of probiotic yogurt added to glucose oxidase compared to commercial products through microbiological, physical-chemical and metabolic activity analyses. Food Res. Int. 2015, 77, 627-635. [CrossRef]

10. Farvin, K.S.; Baron, C.P.; Nielsen, N.S.; Jacobsen, C. Antioxidant activity of yoghurt peptides: Part 1-in vitro assays and evaluation in $\omega$-3 enriched milk. Food Chem. 2010, 123, 1081-1089. [CrossRef]

11. Kariyawasam, K.M.G.M.M.; Lee, N.K.; Paik, H.D. Synbiotic yoghurt supplemented with novel probiotic Lactobacillus brevis KU200019 and fructooligosaccharides. Food Biosci. 2021, 39, 100835. [CrossRef]

12. Arief, I.I.; Taufik, E. Quality and antioxidant activity of yogurt supplemented with roselle during cold storage. Media Peternak. 2016, 39, 82-89.

13. Ovando, C.A.; Carvalho, J.C.; Vinícius de Melo Pereira, G.; Jacques, P.; Soccol, V.T.; Soccol, C.R. Functional properties and health benefits of bioactive peptides derived from spirulina: A review. Food Rev. Int. 2018, 34, 34-51. [CrossRef]

14. Pizzino, G.; Irrera, N.; Cucinotta, M.; Pallio, G.; Mannino, F.; Arcoraci, V.; Squadrito, F.; Altavilla, D.; Bitto, A. Oxidative stress: Harms and benefits for human health. Oxidative Med. Cell. Longev. 2017, 2017, 8416763. [CrossRef] [PubMed]

15. Habibi, N.M.B.; Fatemizadeh, S.S.; Tavakoli, M. Release of proteolysis products with ACE-inhibitory and antioxidant activities in probiotic yogurt containing different levels of fat and prebiotics. Int. J. Pept. Res. Ther. 2019, 25, 367-377. [CrossRef]

16. Sah, B.N.P.; Vasiljevic, T.; McKechnie, S.; Donkor, O.N. Effect of probiotics on antioxidant and antimutagenic activities of crude peptide extract from yogurt. Food Chem. 2014, 156, 264-270. [CrossRef] [PubMed]

17. Ong, L.; Shah, N.P. Influence of probiotic Lactobacillus acidophilus and L. helveticus on proteolysis, organic acid profiles, and ACE-inhibitory activity of cheddar cheeses ripened at 4, 8, and $12{ }^{\circ} \mathrm{C}$. J. Food Sci. 2008, 73, 111-120. [CrossRef]

18. Ayyash, M.; Al-Nuaimi, A.K.; Al-Mahadin, S.; Liu, S.Q. In vitro investigation of anticancer and ACE-inhibiting activity, $\alpha$-amylase and $\alpha$-glucosidase inhibition, and antioxidant activity of camel milk fermented with camel milk probiotic: A comparative study with fermented bovine milk. Food Chem. 2018, 239, 588-597. [CrossRef]

19. Donkor, O.N.; Henriksson, A.; Singh, T.K.; Vasiljevic, T.; Shah, N.P. ACE inhibitory activity of probiotic yoghurt. Int. Dairy J. 2007, 17, 1321-1331. [CrossRef]

20. Lee, N.K.; Kim, H.W.; Chang, H.I.; Yun, C.W.; Kim, S.W.; Kang, C.W.; Paik, H.D. Probiotic properties of Lactobacillus plantarum NK181 isolated from jeotgal, a Korean fermented food. Food Sci. Biotechnol. 2006, 15, 227-231.

21. Kariyawasam, K.M.G.M.M.; Jeewanthi, R.K.C.; Lee, N.K.; Paik, H.D. Characterization of cottage cheese using Weissella cibaria D30: Physicochemical, antioxidant, and antilisterial properties. J. Dairy Sci. 2019, 102, 3887-3893. [CrossRef] [PubMed]

22. Yang, S.J.; Lee, J.E.; Lim, S.M.; Kim, Y.J.; Lee, N.K.; Paik, H.D. Antioxidant and immune-enhancing effects of probiotic Lactobacillus plantarum 200655 isolated from kimchi. Food Sci. Biotechnol. 2019, 28, 491-499. [CrossRef] [PubMed]

23. Cushman, D.W.; Cheung, H.S.; Sabo, E.F.; Ondetti, M.A. Design of potent competitive inhibitors of angiotensin converting enzyme carboxyalkanoyl and mercaptoalkanoyl amino acid. Biochemistry 1977, 16, 54-84. [CrossRef]

24. ISO 5496: 2006; Sensory Analysis-Methodology_Initiation and Training of Assessors in the Detection and Recognition of Odours; ISO: Geneva, Switzerland, 1992.

25. Karimi, R.; Sohrabvandi, S.; Mortazavian, A.M. Review Article: Sensory characteristics of probiotic cheese. Compr. Rev. Food Sci. Food Saf. 2012, 11, 437-452. [CrossRef]

26. Szabo, M.; Iditoiu, C.; Chambre, D.; Lupea, A. Improved DPPH determination for antioxidant activity spectrophotometric assay. Chem. Pap. 2007, 61, 214-216. [CrossRef]

27. Nicholas, J.M.; Catherine, A.R.E. Factors influencing the antioxidant activity determined by the ABTS•+ radical cation assay. Free Radic. Res. 1997, 26, 195-199.

28. Dziuba, M.; Darewicz, M. Food proteins as precursors of bioactive peptides classification into families. Food Sci. Technol. Int. 2007, 13, 393-404. [CrossRef]

29. Tang, X.; He, Z.; Dait, Y.; Xiong, Y.L.; Xie, M.; Chen, J. Peptide fractionation and free radical scavenging activity of zein. J. Agric. Food Chem. 2010, 58, 587-593. [CrossRef]

30. Kudoh, Y.; Matsuda, S.; Igoshi, K.; Oki, T. Antioxidative peptide from milk fermented with Lactobacillus delbrueckii ssp. bulgaricus IFO13953. J. Jpn. Soc. Food Sci. 2001, 48, 44-50. [CrossRef]

31. Cushman, D.W.; Cheung, H.S. Spectrophotometric assay and properties of the angiotensin converting enzyme of rabbit lung. Biochem. Pharm. 1971, 20, 1637-1648. [CrossRef]

32. Cavalheiro, G.F.; Baptista, D.P.; Galli, B.D.; Negrão, F.; Eberlin, M.N.; Gigante, M.L. High protein yogurt with addition of Lactobacillus helveticus: Peptide profile and angiotensin-converting enzyme ACE-inhibitory activity. Food Chem. 2020, 333, 127482. [CrossRef] [PubMed]

33. Chen, G.W.; Tsai, J.S.; Sun Pan, B. Purification of angiotensin I-converting enzyme inhibitory peptides and antihypertensive effect of milk produced by protease-facilitated lactic fermentation. Int. Dairy J. 2007, 17, 641-647. [CrossRef]

34. Vasiljevic, T.; Shah, N.P. Probiotics from metchnikoff to bioactives. Int. Dairy J. 2008, 18, 714-728. [CrossRef]

35. Habibi, N.M.B.; Tavakoli, M.; Fatemizadeh, S.S. Investigation on the effect of fat content and prebiotic compound on proteolysis rate, ACE-inhibitory and antioxidant activity of probiotic yogurt. J. Appl. Microbiol. Food Ind. 2017, 3, 16-29.

36. Erkaya-Kotan, T. In vitro angiotensin converting enzyme (ACE)-inhibitory and antioxidant activity of probiotic yogurt incorporated with orange fibre during storage. J. Food Sci. Technol. 2020, 57, 2343-2353. [CrossRef] 
37. Donkor, O.N.; Henriksson, A.; Vasiljevic, T.; Shah, N.P. Probiotic strains as starter cultures improve angiotensin-converting enzyme inhibitory activity in soy yogurt. J. Food Sci. 2005, 70, 375-381. [CrossRef]

38. Cheon, M.J.; Lim, S.M.; Lee, N.K.; Paik, H.D. Probiotic properties and neuroprotective effects of Lactobacillus buchneri KU200793 isolated from Korean fermented foods. Int. J. Mol. Sci. 2020, 21, 1227. [CrossRef] 